Molloy, L. (2014) Digital curation skills in the performing arts: an investigation of practitioner awareness and knowledge of digital object management and preservation. International Journal of Performance Arts and Digital Media, 10(1). pp. 7-20.

Copyright (c) 2014 Taylor \& Francis

A copy can be downloaded for personal non-commercial research or study, without prior permission or charge

Content must not be changed in any way or reproduced in any format or medium without the formal permission of the copyright holder(s)

When referring to this work, full bibliographic details must be given

http://eprints.gla.ac.uk/93884

Deposited on: 10 February 2015

Enlighten - Research publications by members of the University of Glasgow http://eprints.gla.ac.uk 


\title{
Digital curation skills in the performing arts - an investigation of practitioner awareness and knowledge of digital object management and preservation
}

\author{
Laura Molloy
}

Humanities Advanced Technology and Information Institute (HATII), University of Glasgow G12 8QJ, Scotland.

Email: Laura.Molloy@Glasgow.ac.uk

\begin{abstract}
This study examines the digital curation awareness and practice of a sample of practitioners from the UK performing arts community. Twelve performance arts practitioners from across the UK were interviewed to establish understanding of whether, why and how they create and manage digital objects in the course of their creative work. Detailed qualitative data from this series of one-to-one interviews about the actual and intended digital curation practices of these performance arts practitioners establishes what they understand about sustainable management of digital objects, and also which digital curation activities they actually include in their working processes.
\end{abstract}

This knowledge is supplemented with some preliminary exploration of the types of digital resources that are sought and used by performance arts practitioners, in order to understand whether there is a comparable appetite for the creation and for the reuse of digital objects in this field. Questions in the interview identify the sources used by practitioners when attempting to access digital objects created by others as part of research for their own creative work. This provides a 'practitioner's-eye view' of performance collections, that is to say the resources they use as collections for research, irrespective of the formal designation or intended purpose of such resources.

Here, this enquiry is set into the broader context of digital curation and preservation. The approach to the interviewing is described, findings are discussed and the presence of possible skills and knowledge gaps is presented. Concluding remarks indicate the implications of these indicative findings for the representation of performance arts practice for current and future generations, and suggest useful future areas of enquiry.

\section{Bio}

Laura Molloy is a Preservation Researcher at the Humanities Advanced Technology and Information Institute (HATII) at the University of Glasgow. Following an MA (Hons) Scottish Language and Literature at University of Glasgow, she returned to the University in March 2007 to join the Arts and Humanities Data Service ('AHDS') Performing Arts team. She has since worked on a number of European and UK-based digital preservation and curation projects and is specifically interested in articulating digital curation to all disciplines of research and practice, including those beyond the sciences. Her researcher profile is at http://glasgow.academia.edu/LauraMolloy/. 
A significant proportion of performing arts practitioners produce work outside institutional support structures such as those offered by academia or other large institution such as a national or regional theatre. The wide availability of affordable digital recording devices has allowed such practitioners to become active in the creation of digital objects in the course of researching, rehearsing and creating their work, and also in documenting rehearsals and staged presentations. Digital curation encompasses the processes and skills required for the sustainable management of digital assets throughout their lifecycle and over time, in order to allow the digital object to remain available, findable and useable (Pennock 2007; DCC 2014a). It is apparent, then, that digital curation skills are already necessary for performance arts practitioners. Lacking these skills can have economic consequences for individual practitioners, particularly in the context of their ability to participate in the emerging digital archive, gallery, museum and funder ecosystem, as well as leaving digital assets vulnerable to damage and loss to the detriment of our broader cultural heritage.

Some work has already been undertaken (e.g. Abbott and Beer 2006) to discover the digital curation knowledge and preservation activities of practitioners working within the academic performing arts context, where a certain amount of supporting infrastructure is available. However, such work also highlights the scope for an inquiry into the digital curation and preservation knowledge and processes of performing arts practitioners working outside institutional environments. This article attempts to fill that gap with a description of a series of research interviews with twelve UK-based professional performance arts practitioners who are not primarily supported by academic funding streams or institutional infrastructures. Aside from performers, some respondents work in other creative roles such as playwright, director or choreographer, but all have key responsibility for creative decision-making.

Questions addressed: which disciplines or media the subjects worked in; their involvement as practitioners with the higher education sector; their understanding of the terminology around digital curation, specifically digital preservation and archiving; whether they created their own digital objects as part of professional practice and if so, whether they enacted any digital curation activity upon those objects; the perceived value of their digital objects and the use made of them; and their access to and use of digital objects created by others.

Responses indicated that practitioners highly value the digital objects they create themselves as well as those created by others. They also have expectations of sustained access to these objects. In contrast, however, reported awareness and practice of the principles of sustainable management of digital objects, as promulgated by digital curation, is very low. If the results of the present study are indicative of practice in the larger performance arts sector, many digital objects produced by performing arts practitioners are probably subject to damage or loss.

\section{Background: digital objects and digital curation}

A digital object is an object composed of a set of bit sequences (CCSDS 2012). It encompasses a wide variety of file types (text, video, audio, etc.) and formats (MP3, PDF, JPG, etc.) created and used by performance arts practitioners, and the variety of purposes for which practitioners create and use digital objects (e.g. as an element of a production, note-taking at rehearsal, documentation of a staged presentation, etc.). Digital objects are vulnerable to damage and loss of access, and require pro-active intervention to remain accessible (DPE 2006) and to retain their authenticity. An authentic digital object can be understood as one which is "the same as it was when it was first created" (DPC 2008). 
Digital curation is the active management of digital objects over time. Digital curation is also understood to encompass digital preservation, data and electronic records management, and digital asset management (Yakel 2007). Since 2010, the Digital Curation Centre has provided a Curation Lifecycle Model (see Figure 1) to illustrate the actions and processes required to curate and preserve digital objects (DCC 2014b). This model situates the digital object at its centre, surrounded by the activities continuously necessary throughout the entire lifecycle of the digital object for sustainable curation to take place. These activities are represented by three concentric layers surrounding the digital object. In this way, the model shows that the digital object must be associated with description information, in the form of appropriate metadata, throughout its lifecycle. Representation information is also continuously necessary so that the object and its metadata can be understood and rendered correctly in the user's technical environment. Planning for the management and administration of digital curation actions is also continuously required throughout the object's lifetime. Continuous engagement within the wider digital curation community is also advocated by this model. Surrounding these continuous activities are the sequential actions and processes involved in curating and preserving the object. Conceptualization of the object results in its creation or reception whereupon it becomes manifested as a digital object and can enter the digital curation lifecycle. It is then either selected for preservation or disposed of. Once received, or ingested, into the preservation environment, it can then be sustainably stored in such a way that it is potentially available for re-use and transformation into a new asset, which in turns becomes eligible to enter the curation lifecycle. Each of these sequential actions requires particular skills and competences appropriate to the type of object and context of the curation activity. The study presented in this article is concerned with the presence or absence of these skills and competences among performing arts practitioners. 


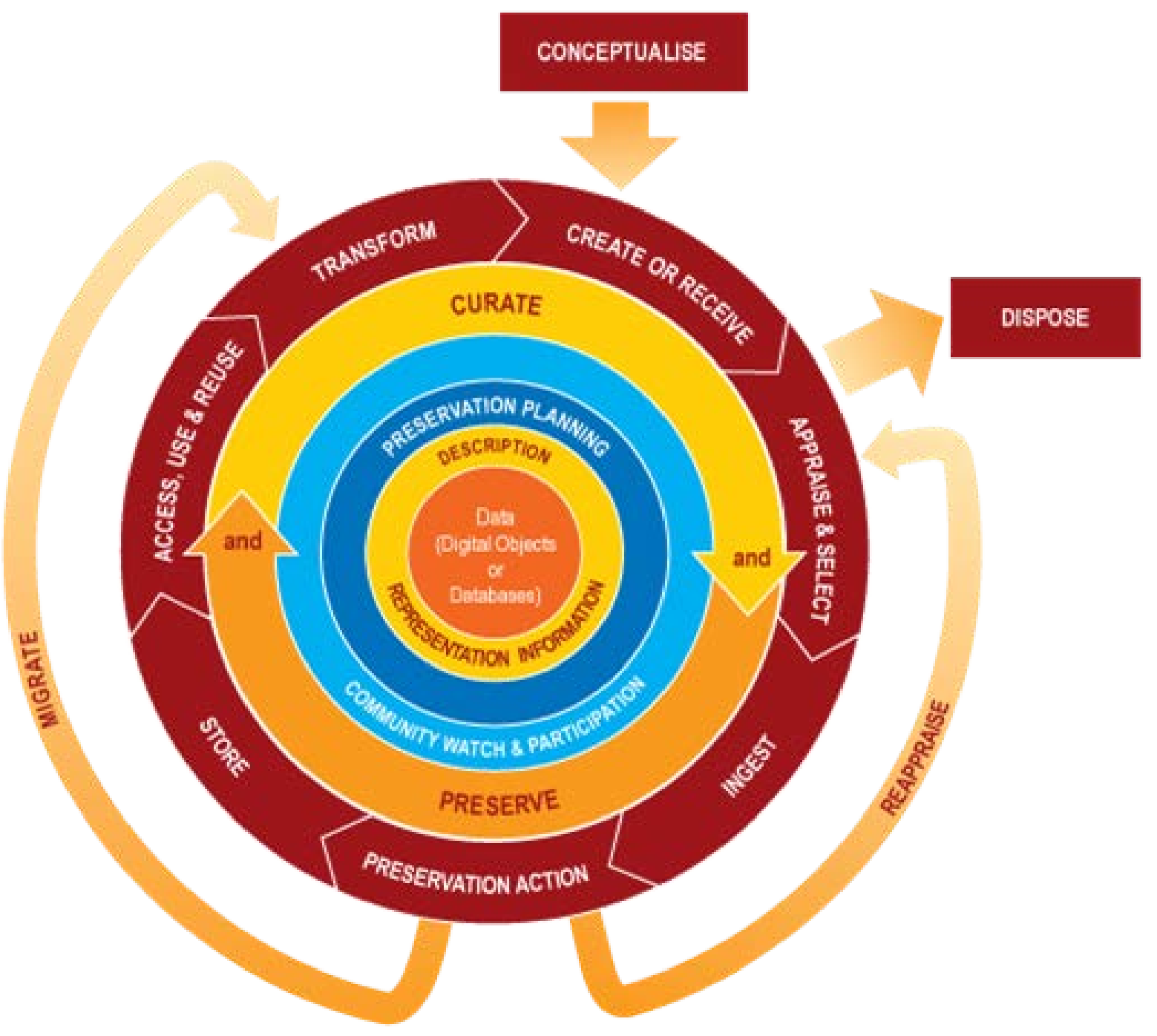

Figure 1: Digital Curation Centre's Curation Lifecycle Model

Digital curation is rapidly becoming recognized by those who fund and care for digital objects in a cultural heritage context as a key set of activities and competences for professional practice within the cultural heritage sector. To participate in the emerging digital cultural heritage ecosystem, performance arts practitioners will increasingly find that the ability to create, manage and preserve digital assets is an important skill.

The term 'curation' has a long-standing association with the care of various types of objects or collections of objects, including our bodies, paperwork, collections of scientific specimens or artworks, and, more recently, the type of collection ubiquitous in both professional and in private life: digital objects (Lee and Tibbo 2011). 'Digital curation' may be a challenging term to employ with clarity in the performing arts due to the established resonance of the term 'curation' in the cultural heritage sector to describe responsibilities such as selecting and interpreting cultural artefacts for public display. In addition, 'digital curation' is frequently used synonymously or interchangeably with 'digital preservation'. To disambiguate, digital preservation "refers to all of the actions required to maintain access to digital materials beyond the limits of media failure or technological change" (DPC 2008). The proximity of meaning between the two terms, then, is clear as a significant amount of the territory claimed by each overlaps. However, as the DCC Curation Lifecycle Model makes clear, digital curation explicitly 
includes the conceptualization of a digital object and extends through the entire lifecycle of the digital object to its capacity to be transformed into new knowledge, thought or work. Digital curation incorporates and is confluent with the aims and activities of digital preservation, which is expressed as a phase within the Curation Lifecycle Model and so the term 'digital curation' offers the most useful shorthand here for the complete and iterative lifecycle of actions or transformation points - including preservation activity - of digital objects.

\section{Methods and approach}

The most important aim for the study outlined in this article is to establish the knowledge and experience of performing arts practitioners about digital curation, including which preservation decisions they make when they are independently responsible for the management of their digital objects and are not being guided by an institutional policy or set of requirements.

\section{Recruitment of respondents}

The initial interviews were intended as a pilot, with only a few subjects, to test the question schema. Two internationally renowned performance makers who happened to be based in within easy physical reach were approached and agreed to participate. Both appeared to engage with and enjoy the interview process and the opportunity to reflect on their creation, management and use of digital objects. Each suggested further subjects likely to engage with the enquiry and so the so-called snowball sampling technique of participant recruitment (Bryman 2012, 424) attracted other participants, and the dataset expanded to a total of twelve respondents. This group of respondents, then, whilst not strictly self-selecting (none were recruited via advertising or responding to an online questionnaire, for example) were entirely recruited through professional performance networks. However, this approach still managed to provide responses from a variety of performance disciplines, as well as a marked range in age and experience of their respective forms.

Whilst all participants at the time of interview were based in Scotland, approximately half originated from and/or trained elsewhere, including England, the USA and Canada (although an exact proportion is not available as this factor was not captured through a direct question) and so the findings should not be considered a study of exclusively Scottish professional practice.

\section{Sample size}

Although the sample used in the current survey $(n=12)$ is clearly too small to be representative of the estimated 400,000 or so professionals employed in the UK performance arts sector, some noticeable trends emerged from the sample which suggest further work in this area would be useful for verification of these results. However, the size of the sample and the method of recruitment limit the ability of the findings to be generalised; a larger supplementary study with a deliberately wider geographical location of professional practice would be required before any claims to represent the UK performance arts sector could be made more conclusively.

\section{Question schema design}

The order and form of questions, and the use of particular terminology on this study are influence by the AHDS Scoping Study (Abbot and Beer 2006). For example, 'preserve' was deliberately the verb employed throughout, instead of, for example, 'manage' or 'curate'. 
However, a decision was made to avoid the use of the term 'digital curation' as there is a distinct set of skills and activities already implied by the term 'curation' in the creative arts sector, as previously discussed, which could cause confusion.

Following the aspects of the AHDS survey, the interviews address the following areas of interest:

\section{Section 1 - Your Work:}

- The type of performance work being made and how it is funded;

- Professional interaction with higher education.

\section{Section 2 - Preservation of Your Work:}

- What performance professionals understand by the notion of 'preserving' their work;

- What is understood by the notion of an archive;

- Whether it is important to preserve work, both in general and to the subject personally;

- What - if anything - respondents do in terms of managing or preserving their digital objects;

- The anticipated lifespan of preserved digital objects;

- The purposes for which they use and/or intend to use the digital objects they create;

- Willingness to share preserved digital objects;

- Experience of digitization;

- Interest in accessing professional archive care for digital objects.

Section 3 - Your Use of Archives:

- Where respondents look to find digital objects in the course of their work;

- The importance of digital objects created by others to their work;

- How often they search for digital objects;

- The purposes for which they use and/or intend to use digital objects created by others;

- Types of objects that are considered useful;

- Digital resources that may be useful to respondent's practice but are not available / accessible.

At the end of each interview, the respondents were also given the opportunity to raise any other themes or questions.

\section{Conducting the interviews}

The 2006 AHDS Scoping Study used an online survey completed by self-selecting respondents and supplemented by a small number of in-person interviews. In contrast, all interviews for the current survey were conducted in person. Due to the confusions likely to emerge when performing arts practitioners were faced with digital curation and preservation terminology, it was anticipated that, for the current study, respondents would prefer to receive clarification of concepts and terminology at the time of responding to the questions. For this reason, an online questionnaire was not deigned suitable for this task. It was hoped that greater respondent confidence in the topic discussed, as supported by in-person interviewing, would elicit richer responses from respondents.

Semi-structured interviewing was employed to ensure that the full framework of questions was addressed, but also to provide ample opportunity to follow any questioning routes suggested by the respondent and capture any further questions, concerns or relevant information from 
each interviewee. This was necessarily a deliberate strategy in the pilot interviews to allow for the adoption of emerging themes in subsequent interviewing if necessary. From the pilot it appeared that the schema did not require substantial revision. Upon analysis, however, the question schema would have benefitted from a few minor changes. Explicit questioning would have been useful to clarify the relative value assigned to those materials used in the research for or in the production of creative work, and the perceived potential of preserved outputs as material for further creative work. This would have provided clearer information on whether practitioners created, used and valued digital objects more in the creative process, or as documentation of the outcomes of that process. Explicit questioning would have also enabled better information on the types of digital object created, both in terms of purpose, such as element of production; documentation, etc. and in terms of file type (text, video, audio, etc.) and format (MP3, PDF, JPG, etc.).

\section{Specialized terminology}

The use of the term 'digital curation' in this context requires careful unpacking to be understood in the sense used by the Digital Curation Centre. For this reason, 'digital preservation' or more frequently, a proxy phrase such as 'preservation of your digital materials' was used during interviews, particularly in Section 2. If the present study intended strictly to understand whether practitioners had heard the term 'digital preservation' before and understood the skills and activities it signifies, there would have been only one positive response given. Questions using the term 'digital preservation' would have benefitted from having a clearer aim, i.e. whether the priority was to assess awareness of the term 'digital preservation' or the familiarity with the processes and knowledge implied by that term such as ensuring files are well described, refreshing carrier media, creating back-ups, and regular file migration. For the purposes of this study, it was more useful to be aware of practitioner understanding of the skills and practices involved in active management of their digital objects, rather than gauging awareness of specialized terms such as 'digital preservation' and 'digital curation', and so proxy phrases to aid understanding were used where necessary. Similarly the terms 'digital archives', 'digital collections' and 'digital resources' were interchangeably used as putative synonyms to facilitate discussion.

\section{Results}

In reporting the results of this study, this article focuses almost exclusively on those aspects of the interviews that relate broadly to aspects of digital curation.

Interview questions: Section 1 - Your Work: The type of performance work being made and how it is funded

The areas of activity were supplied by interview respondents and not prescribed by the interviewer. Three of twelve respondents worked in a single field, area or medium: the others worked in two or more areas. The most frequent number of areas of specialization reported was two (five respondents). The most frequently reported area of activity is as musician (four respondents). Thirteen areas in total were suggested by respondents: playwright, director, stage performer, stage producer, dancer/choreographer, performance artist, live artist, singer, film performer, film-maker, musician, script/screenwriter and songwriter. A clear majority of practitioners in this sample, then, usually worked across more than one area of the performing arts. Findings do not suggest any clear relationship between particular areas of professional practice and levels of knowledge or skill in digital curation. This in turn suggests that, in the 
sample population at least, there are common challenges to sustainable digital curation across all areas of the performing arts.

Funding strategies in the respondent group largely rely upon two main sources of money: selffunding and public funding. Eight respondents of twelve reported 'self-funding' which was defined with participants to mean private income, salary and other funds that are not directly accrued as a result of creative practice. Seven respondents benefitted from Creative Scotland (formerly the Scottish Arts Council and Scottish Screen) funding. Two respondents listed various other sources of public funds. If this trend is replicated across the sector as a whole, it suggests that public funders are potentially in a position of great influence on the priorities and activities of live and performing arts practitioners, given that such a large proportion are in receipt of their support.

It would seem both useful and appropriate, then, for public funders of creative work outside the higher education sector, to consider setting confluent expectations for those digital objects whose creation they have funded in order to encourage their availability and accessibility. Creativity funders currently promulgate no such expectations, but are already operating within the digital ecosystem. They are also reliant upon sustained access to authentic digital objects. For example, applications for Creative Scotland funding are expected to arrive supported by digital documentation of previous creative work in the form of digital audio, video or images. The decision to fund or reject a bid for support is taken by Creative Scotland at least partly on the evidence provided by such digital documentation, indicating the importance in the funding relationship of high quality, well-described digital objects that can be reliably found and accessed. But there are no guidelines provided in Creative Scotland's bidding documentation to guide the practitioner on the creation of high quality digital objects, and storage and sharing solutions recommended by Creative Scotland are commercial cloud services. Such commercial services are highly problematic because they have no obligation to sustain service beyond short-term payment or even, in some cases, respect UK intellectual property rights legislation (Aitken et al 2012).

\section{Interview questions: Section 2 - Preservation of Your Work}

This section of the interviews seeks to establish what practitioners understand by the term 'preservation' in the context of their creative work, and what they it involves. As discussed above, proxy phrases to aid understanding were used where necessary. Of the twelve respondents, one directly asked for clarification of the term 'preservation' and a further eight indicated uncertainty in answering. The most frequent response (eight respondents) was to equate 'preservation' with the creation of digital documentation of live work, without any particular reference to how the resulting digital objects are managed over time. This conflation of object creation and object curation is a key finding of the current study and does much to explain the apparently low levels of digital curation awareness and activity in the sample group. In most cases, the job is considered complete once the digital object is created and burned to CD or DVD. However, good practice in the creation of digital objects is understood as part of overall competent digital curation practice, as articulated by the 'Conceptualise' and 'Create or Receive' phases of the DCC's Curation Lifecycle Model.

Respondents were asked whether it is important for performing arts practitioners in general to preserve their work. All respondents answered yes, seven without further qualification of that response. Three respondents reported ambivalence, with their answer as 'yes' in some scenarios and 'no' in others (for example, that they believed preservation to be important in general but not specifically for their own work). Five respondents discussed the ephemeral 
nature of performance as valuable but only one of those five expressed the view that the value of ephemerality precluded the value of documenting the live work. Preserved traces of performance, i.e. those created both by the respondent and by other practitioners, were described as valuable for various purposes in the course of answers to this question, including value as a resource for research (five respondents), economic or cultural value (four) and as a source of historical knowledge within the discipline (three).

The interviewees were also asked directly whether they preserved their own work and if so, how they went about it. Here, the term 'preserved outputs' was used in the question to attempt to disambiguate between the creation of documentation and the preservation of these objects. If respondents said they did not attempt to preserve their own work, they were asked for any specific reasons and whether this was something they would like to do in future. Almost all respondents (eleven) claim that they 'preserve' their own work. Consideration of the most frequent responses here indicates that this was largely understood to equate to putting analogue and digital objects into a physical box (eight respondents), and the creation of documentation (explicitly described by seven respondents). Unsurprisingly, these responses largely equating the creation of digital objects with their curation or preservation - echoed those to the first question in this section, where respondents attempted to define the idea of preservation. The only digital preservation task mentioned by seven of the respondents was backing up; three of these responses came from those reporting explicitly that the digital objects they produce are documentation of live performance. Four respondents reported that their work is born-digital; two of them back up their work. There is no particular indication in the responses that those creating digital objects in the course of born-digital work are any more aware of digital curation than those creating digital objects only in the course of documenting their creative work.

Most respondents (ten) are able to describe a particular use for the digital objects they created. Eight respondents value their digital objects for use in promotion or marketing of their creative work. Other uses are noticeably lower, including for commercial release (four respondents), in order to be able to restage performances or to enable artistic development (both reported by three respondents). Other uses of digital objects created by the respondent included: for personal reflection; as raw material for new work; as creative inspiration for new work; as elements of live production; for use in teaching; for communication with remote collaborators; and as evidence for funding applications (each reported by either one or two respondents). There is an appetite for making digital objects created by the respondent available for research by other practitioners: ten respondents are in favour although five respondents are unsure whether their material would be of interest or value to other people.

Overall, then, digital object creation and use is widespread in this sample. In the course of creative practice, digital video is created and stored by nine respondents; digital audio by seven respondents; digital images by six, and texts by four. Only one respondent reported not creating digital objects as part of his own creative practice, but even this respondent reported creating such objects for others and receiving such objects from other people. Eight respondents expect the digital objects they created to be available to them in perpetuity or at least as long as they still wanted access to them.

In this section of the interview, respondents were also asked for their separate definitions of an archive and a digital archive. Over half of all respondents (seven) specify accessibility as an expected or common feature of archives. Six respondents hold the issue of accessibility of content as part of their definition of a specifically digital archive, and five that a digital archive 
implies one that is available for access online. No respondent appears to anticipate a situation where a digital archive may not be accessible to interested users.

Five respondents indicated that they were comfortable with the idea of depositing their objects in a location other than their own workspace or home. This theme of deposit offsite was picked up again later on in this section, when respondents were asked if they would prefer their preserved digital objects to be held in a dedicated central resource, or whether practitioners should each hold their own resources. Respondents are strongly in favour (eleven respondents) of both solutions being available. This was partly due to the recognition of the value of professional skills for the curation and preservation of digital objects: seven respondents reported these skills as a benefit of deposit in an external resource. Six respondents see the ability of an external resource to provide wider access to artists, students, researchers and the general public as another benefit. Four respondents are in favour of the practitioner retaining a copy of digital objects in order to have quick and simple access.

Concerns were raised around control of various parameters when allowing wider access to digital objects: five respondents are concerned about managing user access, intellectual property rights (IPR) or copyright, commercial exploitation, the presentation of objects or a general sense of feeling that the work is under their control. These concerns, however, do not to deter support from these respondents for a dedicated external resource.

Responses in Section 2 demonstrate a pragmatic approach to the creation and use of digital objects. It is often the impression given in academic discourse in the performing arts that practitioners privilege - or at least ought to privilege - the ephemeral live moment over the documented trace, a position supported by Barba (1992), Phelan (1996) and others. However, in the current study this is not a prevalent attitude. All respondents believe that performance arts practitioners en masse should preserve their work. Less than half of the respondents raised the issue of the value of the ephemeral nature of performance at all, and only one respondent expressed the view that the value of ephemerality precluded the value of documenting practice; and even that only in certain situations. All respondents create and use digital objects as part of their practice, and nearly all respondents 'preserve' their own creative work, albeit by understanding this to mean creating documentation and storing physical and digital items in unmanaged storage. No indication of active management of digital objects other than the creation of back-ups was given by any of the interviewees. Whilst the production of back-ups is of course a step in the right direction, there is no evidence of active management plans to sustain either the initial object or the back-up copies. Only one respondent showed awareness of the limited lifespan of carrier media, implying that when objects are stored on carrier media such as DVDs, they are not regularly checked or refreshed. Such choices effectively amount to unmanaged, "benign neglect" (Tibbo 2003). As has been noted in digital curation scholarship, however, "benign" means free from intentional damage; unintentional damage is still likely to occur: "[d]igital objects do not, in contrast to many of their analogue counterparts, respond well to benign neglect" (Ross 2012).

Despite this, however, responses in both Section 2 and 3 indicate a marked appetite for the provision of access to digital objects resulting from performance arts practice. There are high expectations of perpetual access to authentic digital objects. Two thirds of respondents assume that their digital objects will be findable, available (and presumably intact) perpetually, or at least as long as they are of interest. Almost half of respondents consider access to digital objects for the use of the original creator, other practitioners, researchers and/or the public to be an important function of any preservation activity. Over half of respondents expect a performing arts-related archives or collections to be widely accessible, whether digital or not. Nearly all 
respondents are in favour of their digital outputs being accessible to other practitioners for research purposes and most are comfortable with a dedicated, external resource providing and managing this access. All respondents who reported a particular use for their digital objects described using them to bring about an economic benefit: particularly by use of these objects for promotion or marketing of creative work, or by sale as a commercial release.

The overall picture, then, is one where digital objects are considered to be a central part of the processes of production and reception of live and performing arts (as argued by, e.g. Jones 1997; Auslander 2008) and of making a living as an performance arts practitioner; this impression is one that is further supported by the findings of Section 3. In this way, a gap becomes visible between practitioners' ambitions for the longevity and authenticity of their highly-valued digital objects and the likely result of their current digital preservation and curation-related decisions. This is arguably the primary finding of this study.

\section{Interview questions: Section 3 - Your Use of Archives}

In this section, respondents were asked to list any collections, archives or resources related to the performing arts, whether digital or not. Ten respondents supplied examples, either of performing arts-specific resources or more general resources that contained performing artsspecific material. Forty-six resources were named overall; thirty-one specifically provided or held performing arts resources and the remainders were more general resources containing performing arts-related material alongside other material. Two respondents expressed the desire to use libraries in their information-seeking practices for either analogue or digital holdings and described academic libraries as rich resources for their field but noted the difficulties of accessing such libraries without the appropriate academic credentials.

Given a four-point scale ('Extremely', 'Somewhat', 'Not Really' and 'Don't Use Them'), seven respondents rated the use of these digital resources as 'somewhat' important to the research and preparation of their own work. A further three respondents rated them as 'extremely' important. Frequency of use followed a similar pattern: seven respondents reported using digital resources once a week or more, all of whom had described use of these resources as either 'somewhat' or 'extremely' important.

The most common reasons using digital resources in research and practice were for factual research (eight respondents); abstract inspiration (seven respondents) and practical ideas (six respondents). Following the options provided by the AHDS study, respondents were asked what sort of materials would be useful in digital resources for the performing arts. Eleven examples were provided in the question schema and respondents asked to choose those they would find useful. Results are tabulated in Figure 2. Most types of resource were equally popular - only raw data (g.) was chosen by less than half of respondents.

\begin{tabular}{|l|r|}
\hline Type of resource & $\begin{array}{l}\text { Frequency } \\
\text { of rating: } \\
\text { useful } \\
\text { (n=12) }\end{array}$ \\
\hline A. Collections of links to relevant websites & 11 \\
\hline B. Bibliographies relevant to particular subjects & 11 \\
\hline C. Searchable raw materials: text (e.g. play scripts) & 9 \\
\hline D. Searchable raw materials: images & 10 \\
\hline E. Searchable raw materials: video & 11 \\
\hline
\end{tabular}




\begin{tabular}{|r|r|}
\hline F. Searchable raw materials: audio & 10 \\
\hline G. Raw statistical data (e.g. audience figures) & 11 \\
\hline $\begin{array}{l}\text { H. } \\
\text { Analytical or interpretative material (e.g. articles on aspects of } \\
\text { performance) }\end{array}$ & 10 \\
\hline I. $\begin{array}{l}\text { Integrated resources (e.g. text with images, musical scores with } \\
\text { recordings) }\end{array}$ & 11 \\
\hline J. $\quad \begin{array}{l}\text { Materials documenting the final performance or product (e.g. a digital } \\
\text { film, or a video of a dance) }\end{array}$ & 8 \\
\hline K. $\begin{array}{l}\text { Materials documenting the process of creating the performance or } \\
\text { product (e.g. director's notes, rehearsal techniques, costume or lighting } \\
\text { design, recording techniques) }\end{array}$ & \\
\hline
\end{tabular}

Figure 2: Perceived usefulness of different types of digital resource

Digital resources discussed were largely online, but can also be circulated using other channels. CDs and DVDs can be disseminated via peer networks or obtained through purchase or rental. Respondents were given the opportunity to specifically mention their access to and use of offline digital resources. All respondents used offline digital resources in research for and preparation of their creative work. Eight respondents used DVDs and seven used CDs. These were most commonly purchased (six respondents) or borrowed from peers and professional contacts (four respondents).

In this section, then, we see that respondents do not demonstrate particular knowledge or skills in information-seeking practices: for example, they do not discriminate between different types of online resource. Most practitioners rely on searching the open web to find digital resources or objects within these resources. Only one respondent seeks help from an information professional. Respondents reported low levels of library use and those interested in using the library for research reported difficulty in accessing academic libraries. These limits to skill and resource unsurprisingly produce frustration when searching for fairly specialist material.

\section{Discussion of findings}

Pulling together the findings from these sections, then, contributes to a characterization of digital curation awareness and practice in the performance arts sector. A majority of respondents appear to equate the creation of digital objects in the course of their creative process with preservation of their work for the future. Often, performers hope, dream or expect that they have somehow captured - to some, preserved - live and performance arts work when in fact what they have achieved is the creation of partial documentation of one or some aspects of it.

These findings suggest a lack of awareness of the need for the active management articulated by digital curation to keep digital objects accessible over time, or in the words of the Digital Preservation Coalition's Digital Preservation Handbook, "required to maintain access to digital materials beyond the limits of media failure or technological change" (DPC 2008).

If the results of this study are representative of the non-university-based live and performance arts practitioner community more widely, then this is a population of practitioners who make ephemeral work and want to digitally retain traces of that work that will last in perpetuity, ensuring it is widely and reliably available. Furthermore, this population already believes it is effectively preserving these digital traces, and already relies on the sustained existence of these 
traces for economic benefit and to contribute to the creative process. The motivation and the enthusiasm for good digital curation practice are both present; awareness, training and reward structures for improved digital curation practice are currently absent.

This study indicates that performance arts practitioners may urgently need to become aware of the risks to which their digital objects are currently subject. Additionally, training may be needed to give funded practitioners access to sufficient digital curation skills to allow the creation of high quality and sustainable digital objects. Practitioners in possession of such skills will be in a position to make and implement more information choices in their own digital curation practice as well as potentially contributing to a cultural shift within their areas of specialization.

Given their responsibility for administration of public funds, appropriate flagship organizations such as the major arts funding agencies would be appropriate bodies to provide such awareness raising and training. Some existing models may be helpful: the activities described here by practitioners constitute a cycle of creation and use, along with a desire to share digital objects, and to find or access digital objects created by others in order to retain evidence of past work. There is also the possibly for such work to inspire and inform the creation of new work.

Further research in this area might usefully concentrate on the production of a larger, expanded study in order to provide results capable of representing the wider UK performance arts community; the current sample is too small to provide this. The results of a larger study might usefully be mapped against those of the Abbott and Beer study to attempt to ascertain the difference in digital curation awareness and practice between those working within and beyond the university context.

\section{Conclusion}

This study describes the digital curation (including digital preservation) awareness and practices in a small sample of live and performance arts practitioners who work outside institutional contexts. This population reported widespread creation and use of digital objects of various types and for various purposes, and high confidence in its digital curation practices but - critically - showed little awareness of the skills required for competent digital curation. This gap identified between perceived and actual digital curation needs suggests that prized digital objects are currently at risk of damage or loss. This population has little access to technical or skills infrastructure to support improved digital curation practice, and a major public funder of this community does not currently provide motivation in the form of either requirements or rewards to engage in good digital curation practice. There is, then, an apparent need for increased practitioner awareness of the benefits of better management of digital objects and for some attempt at training provision for the community that could be usefully supported by the development of guidance and standard-setting by funders.

\section{References}

Abbot, A. and Beer, E. 2006. Getting to Know Our Audience: AHDS Scoping Study. Glasgow: AHDS Performing Arts.

Aitken, B., McCann, P., McHugh, A. and Miller, K. 2012. Curation and the Cloud: Final Report. London: Jisc. http://www.jisc.ac.uk/media/7/C/1/\{7C1A1FD7-44B4-4951-85A8FC2C4CEB1564\}Curation-in-the-Cloud_master_final.pdf 
Auslander, P. 2008. Liveness: Performance in a Mediatized Culture. 2nd ed. Oxon: Routledge.

Barba, E. 1992. "Efermaele: "That Which Will Be Said Afterwards"." The Drama Review 36 (2): 77-80.

Consultative Committee for Space Data Systems (CCSDS). 2012. Reference Model for an Open Archival Information System (OAIS): Recommended Practice. http://public.ccsds.org/publications/archive/650x0m2.pdf.

Digital Curation Centre (DCC). 2014a. "What is digital curation?" Accessed 10 January. http://www.dcc.ac.uk/digital-curation/what-digital-curation.

Digital Curation Centre (DCC). 2014b. Curation Lifecycle Model. Accessed 10 January. http://www.dcc.ac.uk/resources/curation-lifecycle-model.

Digital Preservation Coalition (DPC). 2008. Digital Preservation Handbook. http://www.dpconline.org/advice/preservationhandbook/introduction/definitions-andconcepts.

Digital Preservation Europe (DPE). 2006. "Why should we care about digital preservation?" Accessed 10 January 2014. http://www.digitalpreservationeurope.eu/what-is-digitalpreservation/.

Jones, A. 1997. “Presence' in Absentia: Experiencing Performance as Documentation”. Art Journal 56 (4): 11-18. College Art Association. http://www.jstor.org/stable/777715.

Pennock, M. 2007. “Digital Curation: A Life-Cycle Approach to Managing and Preserving Usable Digital Information". Article for Library \& Archives 1.

http://www.ukoln.ac.uk/ukoln/staff/m.pennock/publications/docs/lib-arch_curation.pdf.

Phelan, P. 1996. "The Ontology of Performance: representation without reproduction." Chapter 7 in Unmarked: the Politics of Performance. Oxon, Routledge.

Ross, S. 2007. "Digital Preservation, Archival Science and Methodological Foundations for Digital Libraries." Keynote Address at the 11th European Conference on Digital Libraries (ECDL), Budapest, 17 September 2007.

Tibbo, H. 2003. "On the Nature and Importance of Archiving in the Digital Age." Advances in Computers 57: 2-69.

Yakel, E. 2007. “Digital curation.” OCLC Systems \& Services 23 (4): 335-340. 